\title{
Endoscopy reporting standards
}

\author{
Daphnée Beaulieu ${ }^{1}$, Alan N Barkun MD MSc ${ }^{1,2}$, Catherine Dubé MD MSc ${ }^{3}$, \\ Jill Tinmouth MD PhD ${ }^{4}$, Pierre Hallé $\mathrm{MD}^{5}$, Myriam Martel $\mathrm{BSc}^{1}$
}

\begin{abstract}
D Beaulieu, AN Barkun, C Dubé, J Tinmouth, P Hallé, M Martel. Endoscopy reporting standards. Can J Gastroenterol 2013;27(5): 286-292.
\end{abstract}

OBJECTIVES: The Canadian Association of Gastroenterology (CAG) recently published consensus recommendations for safety and quality indicators in digestive endoscopy. The present article focuses specifically on the identification of key elements that should be found in all electronic endoscopy reports detailing recommendations adopted by the CAG consensus group.

METHODS: A committee of nine individuals steered the CAG Safety and Quality Indicators in Endoscopy Consensus Group, which had a total membership of 35 voting individuals with knowledge on the subject relating to endoscopic services. A comprehensive literature search was performed with regard to the key elements that should be found in an electronic endoscopy report. A task force reviewed all published, full-text, adult and human studies in French or English.

RESULTS: Components to be entered into the standardized report include identification of procedure, timing, procedural personnel, patient demographics and history, indication(s) for procedure, comorbidities, type of bowel preparation, consent for the procedure, preendoscopic administration of medications, type and dose of sedation used, extent and completeness of examination, quality of bowel preparation, relevant findings and pertinent negatives, adverse events and resulting interventions, patient comfort, diagnoses, endoscopic interventions performed, details of pathology specimens, details of follow-up arrangements, appended pathology report(s) and, when available, management recommendations. Summary information should be provided to the patient or family.

CONCLUSION: Continuous quality improvement should be the responsibility of every endoscopist and endoscopy facility to ensure improved patient care. Appropriate documentation of endoscopic procedures is a critical component of such activities.

Key Words: Colonoscopy/standards; Electronic reporting; Research report/ standards; Review

$\mathrm{Q}$ uality assurance in digestive endoscopy has become a central preoccupation worldwide, with emerging data linking improved outcomes to good-quality endoscopy (1). Screening for colorectal cancer (CRC) has become common practice and is driving a significant portion of such quality initiatives, more specifically in the practice of colonoscopy. Among others, cecal intubation rate, adenoma detection rate and withdrawal times have all been found to be important quality indicators serving as benchmarks in colonoscopy (2). Moreover, further emphasis has been directed toward the patient's well-being and outcomes, leading to greater interest in patient access to procedures, in the appropriateness and timeliness of procedures, and in the achievement and measurement of patient comfort and satisfaction (3). Continuous quality assurance is impossible without a complete standardized endoscopic reporting system because deficiencies in service, appropriate auditing and benchmarking cannot otherwise be

\section{Les normes des rapports d'endoscopie}

OBJECTIFS : L'Association canadienne de gastroentérologie (ACG) a récemment publié des recommandations consensuelles sur les indicateurs de sécurité et de qualité en endoscopie digestive. Le présent article s'attarde sur la détermination des principaux éléments qui devraient figurer dans tous les rapports électroniques d'endoscopie détaillant les recommandations adoptées par le groupe consensuel de l'ACG.

MÉTHODOLOGIE : Un comité de neuf personnes a dirigé les indicateurs de sécurité et de qualité du groupe consensuel d'endoscopie de l'ACG, formé d'un total de 35 personnes ayant droit de vote qui avaient des connaissances sur les services d'endoscopie. Ils ont procédé à une analyse bibliographique détaillée des principaux éléments qui devraient figurer dans un rapport d'endoscopie électronique. Un groupe de travail a analysé le texte intégral de toutes les études sur des adultes et des humains publiées en anglais ou en français.

RÉSULTATS : Les éléments à inclure dans le rapport normalisé sont le nom et le montant de l'intervention, le personnel présent, la démographie et l'historique des patients, les indications de l'intervention, les comorbidités, le type de préparation intestinale, le consentement à l'intervention, l'administration de médicaments avant l'endoscopie, le type et la dose de sédatif utilisé, l'étendue et l'exhaustivité de l'examen, la qualité de la préparation intestinale, les observations pertinentes et les résultats négatifs pertinents, les effets indésirables et les interventions en résultant, le confort du patient, les diagnostics, les interventions endoscopiques effectuées, le détail des échantillons pathologiques, le détail des dispositions de suivi, les rapports de pathologie connexes et, si elles sont disponibles, les recommandations de prise en charge. Le résumé de l'information devrait être fourni au patient ou à sa famille.

CONCLUSION : L'amélioration continue de la qualité devrait incomber à chaque endoscopiste et établissement d'endoscopie afin de garantir de meilleurs soins aux patients. La consignation convenable des interventions endoscopiques est un élément essentiel de ces activités.

easily monitored over time. The effectiveness and safety of endoscopic procedures depend on the quality of the examination, with a growing body of evidence suggesting that the quality of colonoscopy in clinical practice varies greatly (4), including in Canada (5). With this in mind, the Canadian Association of Gastroenterology (CAG) undertook and recently published consensus recommendations on safety and quality indicators in digestive endoscopy (3). The current document serves as a complementary, stand-alone, detailed listing and justification for the endoscopy reporting standards adopted by the CAG, while remembering that a complete report of the procedure performed should be given to the patient on the same day the endoscopy is performed (6).

\section{METHODS}

A committee of nine individuals steered the CAG Safety and Quality Indicators in Endoscopy Consensus Group, which had a total

\footnotetext{
${ }^{1}$ Division of Gastroenterology; ${ }^{2}$ Department of Epidemiology and Biostatistics and Occupational Health, McGill University Health Centre, McGill University, Montreal, Quebec; ${ }^{3}$ Division of Gastroenterology, University of Calgary, Calgary, Alberta; ${ }^{4}$ Division of Gastroenterology, Sunnybrook Health Sciences Centre, University of Toronto, and the Institute for Clinical Evaluative Sciences, Toronto, Ontario; ${ }^{5}$ Division of Gastroenterology, Saint-Sacrement Hospital, Quebec City, Quebec

Correspondence: Dr Alan N Barkun, Division of Gastroenterology, The McGill University Health Centre, Montreal General Hospital site, 1650 Cedar

Avenue, Room D7-185, Montreal, Quebec H3G 1A4. Telephone 514-934-8309, fax 514-834-8531, e-mail alan.barkun@muhc.mcgill.ca
}

Received for publication October 4, 2012. Accepted November 5, 2012 
membership of 35 voting individuals with knowledge on the subject relating to endoscopic services. This multidisciplinary group included gastroenterologists, surgeons, gastroenterology nurses, health policy experts and a lawyer. In addition, nine subcommittees were mandated to address specific issues in greater detail, including a group that was tasked with reviewing the literature pertaining to endoscopy reporting standards. The methodology behind the consensus group process has been described in the CAG consensus guidelines on safety and quality indicators in endoscopy (3). The present article will focus specifically on the identification of key elements that should be found in all electronic endoscopy reports and the resulting recommendations adopted by the CAG consensus group.

\section{Literature search}

A comprehensive literature search was performed in several databases including Ovid MEDLINE, Embase, the Cochrane Library and ISI Web of Knowledge from 1980 to March 2012. All databases were searched using a validated search string specific to colonoscopy and quality reporting. Recursive searches and cross-referencing were also performed; manual searches for articles were performed after the initial search. All full-text, published, adult and human studies in French or English were included. Details regarding the consensus conference and voting have been reported previously (3).

\section{RESULTS/DISCUSSION}

The relevant statement pertaining to the content of the standardized report can be found in the main consensus meeting document reported previously (3). Detailed below are the results of the literature search leading to the justification of the different items to be entered in a standardized report as listed in Table 1.

\section{Components to be entered into the standardized report}

Identification of procedure, timing, and procedural personnel: Type of procedure, date and time of procedure and name of endoscopists and assistants are elements that should be documented in each endoscopic report.

Patient demographics and history: There are differences in the incidence rate of adenomas and mortality of CRC based on age and sex. Therefore, they are important risk factors that should be documented in the standardized electronic report to enable meaningful analysis of adenoma detection rates and prevalence estimates (7).

Indication(s) for the procedure: Colonoscopists should be familiar with the appropriate indications for colonoscopy. Screening and surveillance for colonic neoplasia represent the most common indications for a colonoscopy; emphasis is, therefore, made on specific quality-control issues relative to these two indications (8). Statement 3 from the CAG consensus guidelines (3) states that "endoscopic procedures are performed for an appropriate, clearly documented indication, consistent with current, evidence-based guidelines". The indication for every procedure should be documented in the procedure report, and the indication should be consistent with accepted guidelines to ensure continuous quality improvement. There is evidence that the diagnostic yield of endoscopy is significantly increased when consensus guidelines for appropriate indications are outlined and followed; recent experience also suggests that such practice facilitates appropriate triaging of requests amid already stretched endoscopic resources with the advent of population-based CRC screening (AN Barkun, personal communication). More positive outcomes arise when procedures are performed with appropriate indications. Consensus guidelines provide explicit statements of appropriate indications for endoscopic procedures (9). Unfortunately, studies indicate that $11 \%$ to $39 \%$ of endoscopic procedures are performed for inappropriate indications (9), and that surveillance endoscopies may be performed at inappropriate intervals or unnecessarily. It appears that a lack of knowledge by the endoscopists about the proper intervals is an important factor. Even those who are fully aware tend to not respect guidelines and perform surveillance colonoscopy sooner than recommended (10). In all cases, a nonstandard indication should be clearly
TABLE 1

Required endoscopy report elements

Report field
1. Type of procedure
2. Date and time of procedure
3. Name of endoscopist
4. Name(s) of assistant(s)
5. Age and sex of patient
6. Indications(s) for procedure
7. Comorbidities
8. Type of bowel preparation
9. Documentation of consent
10. Type and dose of sedation used
11. Other medication and related information
12. Extent and completeness of examination
13. Quality of bowel preparation
14. Relevant findings
15. Pertinent negatives
16. Adverse events and resulting interventions
17. Patient comfort
18. Diagnoses
19. Endoscopic interventions performed
20. Details of pathology specimens
21. Details of follow-up arrangements
22. Appended pathology report(s), when available
23. Management recommendations
24. Information provided to patient and/or family

justified in the report. The American Society for Gastrointestinal Endoscopy and the United States Multi-Society Task Force on Colon Cancer have published appropriate indications for colonoscopy (2), as has the CAG, with corresponding suggested target wait times (11). In addition, the appropriateness of screening or surveillance intervals for colonoscopy screening need be assessed according to contemporary guidelines that have recently been updated (12).

Comorbidities: Physical status classifications of The American Society of Anesthesiologists (ASA) have been used by clinicians for more than 50 years to predict perioperative morbidity and mortality. Although this tool has not been validated by studies in digestive endoscopy, the classification is widely accepted as a surrogate of comorbidity (7). The classification category serves to modify the setting and enhance precautions when needed. For example, patients with ASA class 3 or higher are considered to be at high risk for cardiopulmonary events, and endoscopists should consider performing procedures on ASA class 3 patients in a setting that can accommodate adverse events (8).

Type of bowel preparation: The type of bowel preparation should be recorded in each report, and should also address whether a same-day or split-preparation approach was used $(13,14)$.

Consent for the procedure: Documentation of consent is a component that also needs to be entered in the endoscopy report; the CAG consensus indicated in statement 1 that "For a patient to give a physician informed consent to perform an elective endoscopic procedure, the patient must be advised, in a timely fashion, of all relevant information about the procedure, its risks, benefits and alternatives, if any, and be given an opportunity to ask questions that the physician must answer" (3). Lieberman et al (2) further suggest that obtaining consent from the patients is an important component of quality that needs to be documented in the endoscopic report. The risks of endoscopic procedures include bleeding, perforation, infection, adverse events due to sedation, bad diagnosis, missed lesions and other complications. Some have suggested that the informed consent that notifies the patient of all these significant adverse events and the possibility of failure to 
detect neoplasia in the colon even if present should be documented in the standardized colonoscopic report (8) in addition to a documented discussion of alternatives, when available.

Pre-endoscopic administration of medications: Any such relevant administration should be recorded; however, with regard to antibiotic prophylaxis, clinically significant infections following a colonoscopic procedure are very rare. Thus, evidence that supports such administration is very limited - in fact, no standard recommendations currently exist for such practice $(15,16)$.

Type and dose of sedation used: The method and intended level of sedation should be recorded in all cases (8). Colonoscopy reports should indicate whether anesthesia or nursing staff participated in the administration of sedation. Objectives and guidelines have been described in detail elsewhere (17). Some of the objectives include assuring the patient's well-being, providing sedation adequate for the intervention and allowing the patient to recover his/her initial state after the procedure. It has been shown that the use of sedation increases rates of cecal intubation and polyp detection (18). Appropriate sedation also favourably influences both completeness and the risk of acute complications (19). It is reasonable to believe that sedation would render the procedure more tolerable to the patient, in turn improving the potential results of polyp and adenoma detection rates of the procedure, although the practice of sedation and the medications used vary widely across the world.

Extent and completeness of examination: Cecal intubation rates have been reported in previous quality assurance studies (20). Completeness of the colonoscopy is critical to the adequacy of the examination and its benefits with regard to detection of neoplasia $(5,21)$, and perhaps favour the subsequent prevention of cancer as recently suggested (22). From the pertinent quality indicators described previously (3), visualization of the cecum by notation and photodocumentation of landmarks should appear in every report to confirm completion of the procedure. In colonoscopy, cecal intubation is a good indicator of completeness and recognized performance, which is pertinent for future practice evaluations $(2,23)$. Moreover, identification of two of the following key landmarks should also be included in the standardized electronic report: the appendiceal orifice, the ileocecal valve or the cecal strap fold (2). Photography of the landmarks, although subject to interpretation, is also recommended and will be discussed further below. If for some reason the procedure cannot be completed, this must be documented in the report and another colonoscopy should be scheduled.

It has also been recommended that the following times should be recorded: insertion of the endoscope; start of withdrawal from cecum; and complete withdrawal of the endoscope (8). Withdrawal time is the time required to withdraw the colonoscope from cecal intubation to the anus. There exists a significant correlation between withdrawal time and adenoma and polyp detection (although the significance of those detected has been brought into question); thus, sufficient time must be allotted for the removal of the scope $(24,25)$. Withdrawal time has been shown to increase the detection rate of colonic neoplastic lesions with varying reported threshold values. The most influential publication on this topic suggested the endoscopist spend at least $6 \mathrm{~min}$ or more withdrawing the scope. Thus, the CAG has set the mean withdrawal time at 6 min under normal conditions (no tissue sampling or staining, and no polypectomy) (2). However, many factors, such as the length of the intestine and bowel preparation quality, can affect withdrawal time, influencing the polyp detection rate (26). Therefore, withdrawal time should be considered as an indirect quality indicator of colonoscopy and, although currently adopted by many workgroups and societies, including the CAG, may not withstand the test of time as a useful, independent quality indicator. The documentation of withdrawal time should be in every report, but is less interpretable and of less use when applied to a procedure requiring biopsies or polypectomy. $(2,27)$. Reasons for a withdrawal time shorter than recommended should be documented in the standardized electronic report.

Finally, for the procedure to be complete, retroflexion can be considered, although routine rectal retroflexion during colonoscopy has been shown to carry a low yield for the detection of advanced neoplasia (28).
Quality of bowel preparation: The quality of bowel preparation should be recorded in all cases, using a validated scale (at the very least in the context of a population-based screening program) $(29,30)$ because it is a necessary indicator in determining the appropriate interval for the examination (8). Indeed, the quality of bowel preparation is an indicator of quality and performance recognized and relevant for the evaluation of colonoscopic practice (2). Poor bowel preparation is a major reason for an inability to meet preplanned appropriate screening intervals. It can also lead to prolonged cecal intubation and withdrawal time, and a reduced polyp detection rate (2). Good bowel preparation is also associated with a higher proportion of complete colonoscopies (19). Current guidelines established by the United States Multi-Society Task Force for Colonoscopy state that a preparation should be judged adequate if polyps $\geq 5 \mathrm{~mm}$ can be detected (7). Suggested intervals for repeat examinations in case of poor colonic preparations have recently been proposed (12).

Relevant findings and pertinent negatives: Appropriate description of findings is required; a number of descriptor compendia exist (31). In the case of colonic polyps, characteristics to be recorded include polyp number, size and location. This information will permit the subsequent tracking of adenoma detection rates. Studies have shown that polyps and adenoma removal results in a lower than expected incidence of CRC (22). The incidence is lowered to $76 \%$ to $90 \%$ after polypectomy $(32,33)$. More than $95 \%$ of the detected polyps should be removed and sent to pathology. Small hyperplastic-appearing rectal polyps ( $<5 \mathrm{~mm}$, sessile) do not require removal (34). If in doubt, a biopsy should be obtained to confirm the histology of the polyp and its location adequately described $(7,8)$. Depending on the nature of the findings, where appropriate, widely recognized scales to better standardize reporting should be used (eg, the Forrest score in peptic ulcer bleeding [35], or the Mayo score for inflammatory colitis [36]). Pertinent negatives should also be specified where appropriate.

Adverse events and resulting interventions: In each report, there should be documentation of unplanned interventions during the procedure, if applicable. The record should reflect any intra- and postprocedural complications. Currently, no link exists between postprocedural complications that were not recognized at the time of the procedure and the endoscopic report in most units. Optimally, such a link between databases should be established. Indeed, a system should be set up to report and evaluate these postprocedure complications so that they can be discovered and corrected. The optimal standardized time for capturing such events remains controversial (37). Furthermore, adverse events should be recorded using relevant, standardized descriptions and validated scales $(38,39)$.

Patient comfort: Patient comfort during the procedure should be documented, ideally using validated scales (40).

Diagnoses: The diagnosis should take into consideration all of the available data derived from history, laboratory, radiographies and new endoscopic findings. It should also be performed using standard terminology and validated scales, if appropriate (for example, the Los Angeles classification scoring of esophagitis) (41).

Endoscopic interventions performed: A clear statement of what the endoscopist did during the procedure should be included in the report, again using standard terminology and descriptions. Also, the number and location of the biopsies performed should be recorded.

Details of pathology specimens: The details of the polyps seen and resected should be part of all reports, with a clear description of whether tissue was sent to pathology and what sample is present in each container.

Details of follow-up arrangements: Details about the recommendations for discharge planning and follow-up arrangements should be included with the colonoscopy report and given to the patient. Endoscopists should indicate the expected interval for the next examination, recommended according to contemporary published surveillance guidelines, or if there is reason to deviate from the guidelines, as stated above (2). Whenever biopsies are performed, final recommendations and treatment are made after the pathology results 
are reviewed; however, the endoscopist should ensure that there is a system in place to communicate these final arrangements to both the patient and referring clinician (8).

Appropriate management following endoscopy (in addition to appropriate preparation before the procedure) must also be documented when managing a patient undergoing antithrombotic therapy. Guidelines have been proposed by the American Society for Gastrointestinal Endoscopy (42), the British Society of Gastroenterology (43), the American College of Chest Physicians (44), and the American College of Cardiology/American Heart Association (45). Practitioners need to stay up to date with the introduction of newer medications and recommended optimal times of discontinuation, if indicated, such as new anticoagulants such as dabigatran (46).

Appended pathology reports(s), when available: No specific mechanism or manpower support currently exist in most Canadian units to allow for a reliable and complete link between the databases that generate the endoscopic report and the pathology results (47). An effort must be made to ensure that the pathology results are conveyed in a timely fashion to both endoscopist and referring physician, and that adequate documentation be ensured through providing some form of linkage of endoscopic findings and subsequent histological characterization.

Management recommendations: When necessary, the management of antithrombotic prophylaxis should be outlined in the report as discussed above (42).

Information provided to patient and/or family: The CAG consensus specified in statement 9, further discussed below, that all patients should be provided with written information regarding the procedure the same day. The information should include procedural findings, follow-up plans and treatment, symptoms to watch for and the next steps that should be taken (3).

\section{THE ENDOSCOPY REPORT PLATFORM}

\section{Need for an adapted system}

A complete endoscopy report is an essential element of a quality endoscopy service. Previously, narrative reporting was commonly used, but it is often associated with incomplete documentation, variations in the recording of positive findings, pertinent negative findings and other procedural details. An electronic standardized endoscopy report template results in effective communication of procedural findings, and successful practice audit and quality improvement processes that are exceedingly difficult to achieve using narrative or written reports. This is why the CAG consensus indicated in statement 20: "Endoscopic procedures should be reported in a standardized electronic format, including mandatory reporting fields, to provide full documentation of all necessary clinical and quality measure" (3). A country-wide initiative is currently underway in an attempt to define national synoptic reporting standards in digestive endoscopy ( $\mathrm{P}$ Rossos, personal communication).

Colonoscopy reporting practices of clinicians are highly variable and often suboptimal. Studies have revealed substantial variation in the completeness of endoscopic text reports and in adherence to the use of standard terms. Inconsistent endoscopy reporting includes differences in disease definition such as the description and quantification of mucosal inflammation in ulcerative colitis (48). Reports also show marked variations in the completion of different report elements. The items that often score most poorly are demographic data, patient history, preparation quality with visualization and procedure interpretation. Other report elements that vary greatly include lesion identification and removal, and sedation practice (49). The use of grading systems is suggested; however, to date, the recommended systems are disease specific and require further assessment before adopting them for use in standardized endosccopy reporting.

It is well established in the literature that a well-structured reporting system leads to improved completeness in endoscopy reports, and this can be achieved with a standardized electronic reporting system. The value of electronic reporting also lies in its ability to establish a method and process of increased standardization facilitating timely audits, benchmarking and data archiving.

Standardization of electronic reports includes the mandatory reporting of elements. Electronic data, such as digital transcripts of dictated reports, are preferable to handwritten reports but are still considered inferior to a standardized electronic report.

\section{Benefits of an electronic report}

Comparing handwritten, dictated and computerized reports, Soehkoe et al (50) showed that preparing an endoscopy report using a computergenerated method does not take more time than preparing a report the conventional way, such as with dictation. Electronic reports also offer some advantages over handwritten and dictated reports. To have a complete endoscopic report, clinicians need to capture images of the gastrointestinal (GI) tract, for example, as recommended by the European Society for Gastrointestinal Endoscopy (51). In handwritten and dictated reports, images are printed on photographic paper with ordinary printers, a practice that is expensive. One of the advantages of a computer-generated report is that an unlimited number of endoscopic images can be stored digitally in the electronic database. Realtime comparison with previously captured images is also possible with such a system. Although not the aim of the study, the authors determined that the standardized text in computerized, predefined reports also enables statistical analysis of endoscopic findings, whereas the use of free-text handwritten and dictated reports does not do so in such a direct way. Therefore, the capacity to store all endoscopic findings, including endoscopic images, in a database offers an additional advantage over handwritten and dictated reports. Many examples of such computer-generated, predefined electronic reports are now used globally $(52,53)$, with examples of systems that offer a quick, userfriendly way of report writing; however, none produce a synoptic report. Furthermore, studies have shown that a standardized electronic report system produces superior reports in terms of completeness of the endoscopic report compared with free-text reports that are handwritten or dictated (52).

Cost of electronic reporting: Groenen et al (54) assessed the costs of the different ways to generate endoscopic reports, comparing handwritten, dictated and computerized reports. It was concluded that electronic reports were beneficial and cost effective in the long run. Although they require a larger initial acquisition cost compared with other means of reporting, electronic reports gain their cost advantage after five years. The high initial investment is due to the need for hardware, software and linkage to other medical computerized systems. After five years, the cost per report declines below the cost of handwritten and dictated reports. The more conventional ways of reporting require more personnel, increasing the risks of errors and costs. Electronic reporting minimizes material, workspace and personnel costs. Furthermore, the cost of printing and storing images is less in computerized reporting because only storage capacity is required to store the recommended number of images per procedure.

All the aforementioned advantages were taken into account by the CAG consensus group, which recommends the routine use of a standardized electronic reporting system in digestive endoscopy.

\section{Electronic image capture}

High-quality videoendoscopic imaging is currently available to endoscopists to document photographs of specific parts of the GI tract during the course of an endoscopic examination. Imaging can be used to confirm cecal intubation. However, a problem occurs due to the nonspecific appearance of cecal landmarks in many individuals (55). Variations in normal cecal anatomy limit the extent to which still imaging can be used as a definite indication of cecal intubation, whereas multiple still photographs can be more convincing. Photographing characteristic features of the GI tract can also render the photographs more conclusive. Rex (56) suggested that the cecal view is best taken when the valve lips are en face or a notch in the 
valve contour is visible. Additionally, the appendiceal orifice is best taken from a sufficient distance to capture the 'crow's foot' appearance of the cecum around the orifice (56). Finally, a photograph of the terminal ileum will be most convincing when it captures the following specific features: valvulae encircling the bowel, lymphoid hyperplasia, fine granular appearance and absence of normal vascular pattern found in the rest of the colon (56). Despite following these recommendations, variations in landmarks and in bowel preparation quality are such that confirmation by photodocumentation of cecal intubation cannot be convincing every time. On the other hand, cecal videotaping is a highly convincing method to document cecal intubation. It is also inexpensive, but one of its limitations is that it complicates retrieval of information. Hence, still photography, although not ideal, is often considered the most practical way to document cecal intubation (57). The European Society for Gastrointestinal Endoscopy has suggested a series of eight reference images for the documentation of upper endoscopic procedures and another set of eight images for colonoscopies (51).

\section{IMPACT OF IMPLEMENTING EDUCATION IN REPORTING}

Lieberman et al (4) conducted a study to determine the quality of colonoscopy reporting in diverse practice settings because, as mentioned above, to improve colonoscopy quality, reports must include key quality indicators that can be monitored. As expected, there is significant variation in the quality of colonoscopy reports across diverse practices. Even with the use of a standardized computergenerated reports, many quality indicators were missing, which could harm quality improvements in the practice of colonoscopy. Hence, implementing education in reporting is crucial for continuous quality improvement in endoscopy. In a study performed in a Canadian institution, various deficits in reporting were outlined and recommendations to improve the appropriate use of an existing reporting system were made, leading to a documented postintervention quality improvement (47). Measurement of quality indicators in clinical practice can identify areas for quality improvement and permit good monitoring of the clinical practice (4).

\section{Patient perception and timing of the report}

Statement 9: "All patients, on discharge, are given written information regarding the procedure findings, plans for treatment and followup, worrisome symptoms to watch for, and steps to be taken" (3).

A study conducted by Spodik et al (6) has shown that providing an endoscopy report to patients after an endoscopic examination diminishes postprocedure anxiety, improves recollection of findings and recommendations, and increases the level of compliance to the given recommendations and follow-up plan (6). Thus, when a patient is discharged, an endoscopy report with the details of the procedure should be provided at that time. Furthermore, information should also be transmitted to any physician providing subsequent care. As recommended by the CAG, the endoscopy report should contain the following information: description of key findings, interventions, complications and sedation, description of symptoms of potential complications, instructions of actions to be taken and contact details if symptoms of complications arise, instructions on resumption of anticoagulants when relevant, and instructions for follow-up (3). Possession of a complete endoscopy report is more favourable than a verbal review alone because, in this case, the patient can freely refer back to the report, reducing the uncertainty and increasing the adherence to the recommended course of action following the examination. Reasons for this might be because the report clarifies the findings, interventions and recommendations that would otherwise only be relayed verbally. Also, better recall of the information is possible when the stress and medication of the procedure have less influence. Finally, a report serves as a concrete validation of the procedure (6). Availability of the report may also facilitate unscheduled postprocedural medical intervention at a different site, Each endoscopy facility should, therefore, implement policies that specify the information to be included in the discharge report, including, but not limited to the details of follow-up arrangements that have been made and the person responsible for arranging the follow-up plan.

Statement 21: "Endoscopy facilities should implement policies to monitor and ensure the timeliness and completeness of procedure reporting" (3).

Issues pertaining to this recommendation have been addressed above.

\section{CONCLUSION}

Reduction in the variation of quality is of primary importance for endoscopy practice. High-quality endoscopy requires more than a good performance on the part of the endoscopist. From the initial patient interaction with a health care provider, the delivery of high-quality endoscopy services must be provided in an optimal and cost-effective manner following established quality assurance guidelines. Such an approach requires a well-established quality improvement framework, addressing all aspects of endoscopy, such as is outlined in the Global Rating Scale, the Canadian version of which will soon be published (C Dubé, personal communication). Continuous quality improvement should be the responsibility of every endoscopy facility to ensure improved patient care. Quality assurance for endoscopy requires that only competent physicians be given privileges to practice, and that continuous implementation of education in reporting and other areas of endoscopy is performed. Endoscopy units should regularly participate in a continuous process of quality improvement. In May 2010, the scarcity of high-grade evidence relevant to endoscopy service delivery was one of the CAG consensus' outcomes. Following this conclusion, participants identified important quality indicators. There was a high level of agreement on key features that should be addressed to improve endoscopy quality among the large multidisciplinary group of health care professionals forming the consensus (3). The present article reviews current evidence and expert consensus on these quality indicators to be used in the process of improving quality in endoscopic reporting and patient care. Following the consensus among experts, the present study suggests a framework for a quality improvement structure in endoscopic units based on explicit recommendations that support systematic monitoring, assessment and modifications in endoscopy service delivery through optimal endoscopic reporting.

\section{REFERENCES}

1. Faigel DO, Pike IM, Baron TH, et al. Quality indicators for gastrointestinal endoscopic procedures: An introduction. Gastrointest Endosc 2006;63(4 Suppl):S3-9.

2. Rex DK, Petrini JL, Baron TH, et al. Quality indicators for colonoscopy. Am J Gastroenterol 2006;101:873-85.

3. Armstrong D, Barkun A, Bridges R, et al. Canadian Association of Gastroenterology consensus guidelines on safety and quality indicators in endoscopy. Can J Gastroenterol 2012;26:17-31.

4. Lieberman DA, Faigel DO, Logan JR, et al. Assessment of the quality of colonoscopy reports: Results from a multicenter consortium. Gastrointest Endosc 2009;69(3 Pt 2):645-53.

5. Baxter NN, Goldwasser MA, Paszat LF, Saskin R, Urbach DR, Rabeneck L. Association of colonoscopy and death from colorectal cancer. Ann Intern Med 2009;150:1-8.

6. Spodik M, Goldman J, Merli K, Walker C, Alpini B, Kastenberg D. Providing an endoscopy report to patients after a procedure: A low-cost intervention with high returns. Gastrointest Endosc 2008;67:103-11.

7. Rex DK, Bond JH, Winawer S, et al. Quality in the technical performance of colonoscopy and the continuous quality improvement process for colonoscopy: Recommendations of the U.S. Multi-Society Task Force on Colorectal Cancer. Am J Gastroenterol 2002;97:1296-308. 
8. Lieberman D, Nadel M, Smith RA, et al. Standardized colonoscopy reporting and data system: Report of the Quality Assurance Task Group of the National Colorectal Cancer Roundtable. Gastrointest Endosc 2007;65:757-66.

9. Froehlich F, Repond C, Mullhaupt B, et al. Is the diagnostic yield of upper GI endoscopy improved by the use of explicit panel-based appropriateness criteria? Gastrointest Endosc 2000;52:333-41.

10. Saini SD, Nayak RS, Kuhn L, Schoenfeld P. Why don't gastroenterologists follow colon polyp surveillance guidelines?: Results of a national survey. J Clin Gastroenterol 2009;43:554-8.

11. Leddin D, Armstrong D, Barkun AN, et al. Access to specialist gastroenterology care in Canada: Comparison of wait times and consensus targets. Can J Gastroenterol 2008;22:161-7.

12. Lieberman DA, Rex DK, Winawer SJ, Giardiello FM, Johnson DA, Levin TR. Guidelines for colonoscopy surveillance after screening and polypectomy: A consensus update by the US Multi-Society Task Force on Colorectal Cancer. Gastroenterology 2012;143:844-57.

13. Barkun A, Chiba N, Enns R, et al. Commonly used preparations for colonoscopy: efficacy, tolerability, and safety - a Canadian Association of Gastroenterology position paper. Can J Gastroenterol 2006;20:699-710.

14. Belsey J, Crosta C, Epstein O, et al. Meta-analysis: The relative efficacy of oral bowel preparations for colonoscopy 1985-2010. Aliment Pharmacol Ther 2012;35:222-37.

15. Banerjee S, Shen B, Baron TH, et al. Antibiotic prophylaxis for GI endoscopy. Gastrointest Endosc 2008;67:791-8.

16. Allison MC, Sandoe JA, Tighe R, Simpson IA, Hall RJ, Elliott TS. Antibiotic prophylaxis in gastrointestinal endoscopy. Gut 2009;58:869-80.

17. Waring JP, Baron TH, Hirota WK, et al. Guidelines for conscious sedation and monitoring during gastrointestinal endoscopy. Gastrointest Endosc 2003;58:317-22.

18. Radaelli F, Meucci G, Sgroi G, Minoli G. Technical performance of colonoscopy: The key role of sedation/analgesia and other quality indicators. Am J Gastroenterol 2008;103:1122-30.

19. Crispin A, Birkner B, Munte A, Nusko G, Mansmann U. Process quality and incidence of acute complications in a series of more than 230,000 outpatient colonoscopies. Endoscopy 2009;41:1018-25.

20. Barclay RL, Vicari JJ, Doughty AS, Johanson JF, Greenlaw RL. Colonoscopic withdrawal times and adenoma detection during screening colonoscopy. New Engl J Med 2006;355:2533-41.

21. Brenner H, Chang-Claude J, Seiler CM, Hoffmeister M. Interval cancers after negative colonoscopy: Population-based case-control study. Gut 2012;61:1576-82.

22. Kaminski MF, Regula J, Kraszewska E, et al. Quality indicators for colonoscopy and the risk of interval cancer. New Engl J Med 2010;362:1795-803.

23. Brenner H, Chang-Claude J, Seiler CM, Rickert A, Hoffmeister M. Protection from colorectal cancer after colonoscopy: A populationbased, case-control study. Ann Intern Med 2011;154:22-30.

24. Leddin D. Canadian Association of Gastroenterology launches human resources planning initiatives. Can J Gastroenterol 2004;18:583-7.

25. Barclay RL, Vicari JJ, Greenlaw RL. Effect of a time-dependent colonoscopic withdrawal protocol on adenoma detection during screening colonoscopy. Clin Gastroenterol Hepatol 2008;6:1091-8.

26. Sanchez W, Harewood GC, Petersen BT. Evaluation of polyp detection in relation to procedure time of screening or surveillance colonoscopy. Am J Gastroenterol 2004;99:1941-5.

27. Imperiale TF, Glowinski EA, Juliar BE, Azzouz F, Ransohoff DF. Variation in polyp detection rates at screening colonoscopy. Gastrointest Endosc 2009;69:1288-95.

28. Overholt BF, Brooks-Belli L, Grace M, et al. Withdrawal times and associated factors in colonoscopy: A quality assurance multicenter assessment. J Clin Gastroenterol 2010;44:e80-6.

29. Saad A, Rex DK. Routine rectal retroflexion during colonoscopy has a low yield for neoplasia. World J Gastroenterol 2008;14:6503-5.

30. Rostom A, Jolicoeur E. Validation of a new scale for the assessment of bowel preparation quality. Gastrointest Endosc 2004;59:482-6.

31. Lai EJ, Calderwood AH, Doros G, Fix OK, Jacobson BC. The Boston bowel preparation scale: A valid and reliable instrument for colonoscopy-oriented research. Gastrointest Endosc 2009;69(3 Pt 2):620-5.

32. Aabakken L, Rembacken B, LeMoine O, et al. Minimal standard terminology for gastrointestinal endoscopy - MST 3.0. Endoscopy 2009;41:727-8.
33. Winawer SJ, Zauber AG, Ho MN, et al. Prevention of colorectal cancer by colonoscopic polypectomy. The National Polyp Study Workgroup. New Engl J Med 1993;329:1977-81.

34. Citarda F, Tomaselli G, Capocaccia R, Barcherini S, Crespi M. Efficacy in standard clinical practice of colonoscopic polypectomy in reducing colorectal cancer incidence. Gut 2001;48:812-5.

35. Rex DK, Kahi C, O'Brien M, et al. The American Society for Gastrointestinal Endoscopy PIVI (Preservation and Incorporation of Valuable Endoscopic Innovations) on real-time endoscopic assessment of the histology of diminutive colorectal polyps. Gastrointest Endosc 2011;73:419-22.

36. Forrest JA, Finlayson ND, Shearman DJ. Endoscopy in gastrointestinal bleeding. Lancet 1974;2:394-7.

37. Schroeder KW, Tremaine WJ, Ilstrup DM. Coated oral 5-aminosalicylic acid therapy for mildly to moderately active ulcerative colitis. A randomized study. New Engl J Med 1987;317:1625-9.

38. Rabeneck L, Paszat LF, Hilsden RJ, et al. Bleeding and perforation after outpatient colonoscopy and their risk factors in usual clinical practice. Gastroenterology 2008;135:1899-906, 1906 e1891.

39. Romagnuolo J, Cotton PB, Eisen G, Vargo J, Petersen BT. Identifying and reporting risk factors for adverse events in endoscopy. Part I: Cardiopulmonary events. Gastrointest Endosc 2011;73:579-85

40. Romagnuolo J, Cotton PB, Eisen G, Vargo J, Petersen BT. Identifying and reporting risk factors for adverse events in endoscopy. Part II: Noncardiopulmonary events. Gastrointest Endosc 2011;73:586-97.

41. Lee TJ, Rutter MD, Blanks RG, et al. Colonoscopy quality measures: Experience from the NHS Bowel Cancer Screening Programme. Gut 2012;61:1050-7.

42. Armstrong D, Marshall JK, Chiba N, et al. Canadian Consensus Conference on the management of gastroesophageal reflux disease in adults - update 2004. Can J Gastroenterol 2005;19:15-35.

43. Anderson MA, Ben-Menachem T, Gan SI, et al. Management of antithrombotic agents for endoscopic procedures. Gastrointest Endosc 2009;70:1060-70.

44. Veitch AM, Baglin TP, Gershlick AH, Harnden SM, Tighe R, Cairns S. Guidelines for the management of anticoagulant and antiplatelet therapy in patients undergoing endoscopic procedures. Gut 2008;57:1322-9.

45. Douketis JD, Bakhsh E. Perioperative management of antithrombotic therapy. Polskie Archiwum Medycyny Wewnetrznej 2008;118:201-8.

46. Fleisher LA, Beckman JA, Brown KA, et al. ACC/AHA 2007 guidelines on perioperative cardiovascular evaluation and care for noncardiac surgery: A report of the American College of Cardiology/American Heart Association Task Force on Practice Guidelines (Writing Committee to Revise the 2002 Guidelines on Perioperative Cardiovascular Evaluation for Noncardiac Surgery): developed in collaboration with the American Society of Echocardiography, American Society of Nuclear Cardiology, Heart Rhythm Society, Society of Cardiovascular Anesthesiologists, Society for Cardiovascular Angiography and Interventions, Society for Vascular Medicine and Biology, and Society for Vascular Surgery. Circulation 2007;116:e418-499.

47. Cheng JW, Vu H. Dabigatran etexilate: An oral direct thrombin inhibitor for the management of thromboembolic disorders. Clin Ther 2012;34:766-87.

48. Beaulieu D, Martel M, Barkun AN. A prospective intervention study of colonoscopy reporting amongst patients screened or surveilled for colorectal neoplasia. Can J Gastroenterol 2012;26:718-22.

49. de Lange T, Moum BA, Tholfsen JK, Larsen S, Aabakken L. Standardization and quality of endoscopy text reports in ulcerative colitis. Endoscopy 2003;35:835-40.

50. Soekhoe JK, Groenen MJ, van Ginneken AM, et al. Computerized endoscopic reporting is no more time-consuming than reporting with conventional methods. Eur J Intern Med 2007;18:321-5.

51. Rey JF, Lambert R. ESGE recommendations for quality control in gastrointestinal endoscopy: Guidelines for image documentation in upper and lower GI endoscopy. Endoscopy 2001;33:901-3.

52. Groenen MJ, Kuipers EJ, van Berge Henegouwen GP, Fockens P, Ouwendijk RJ. Computerisation of endoscopy reports using standard reports and text blocks. Neth J Med 2006;64:78-83. 
53. Hoff G, Ottestad PM, Skaflotten SR, Bretthauer M, Moritz V. Quality assurance as an integrated part of the electronic medical record - a prototype applied for colonoscopy. Scand J Gastroenterol 2009;44:1259-65.

54. Groenen MJ, Ajodhia S, Wynstra JY, et al. A cost-benefit analysis of endoscopy reporting methods: Handwritten, dictated and computerized. Endoscopy 2009;41:603-9.

55. Marshall JB, Brown DN. Photodocumentation of total colonoscopy: How successful are endoscopists? Do reviewers agree? GastrointestEndosc 1996;44:243-8.
56. Rex DK. Still photography versus videotaping for documentation of cecal intubation: A prospective study. Gastrointest Endosc 2000;51(4 Pt 1):451-9.

57. Asfeldt AM, Straume B, Paulssen EJ. Impact of observer variability on the usefulness of endoscopic images for the documentation of upper gastrointestinal endoscopy. Scand J Gastroenterol 2007;42:1106-12. 


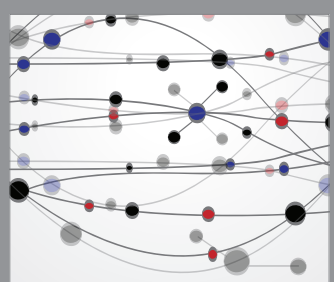

The Scientific World Journal
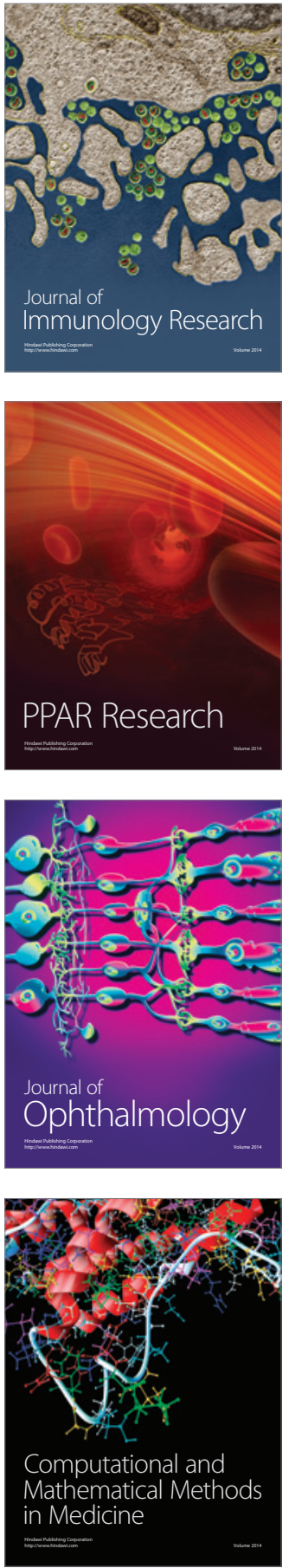

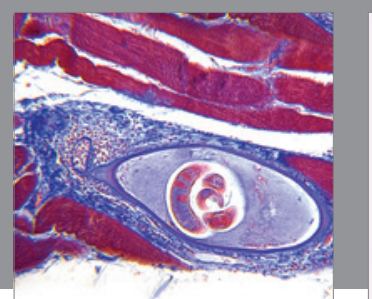

Gastroenterology Research and Practice

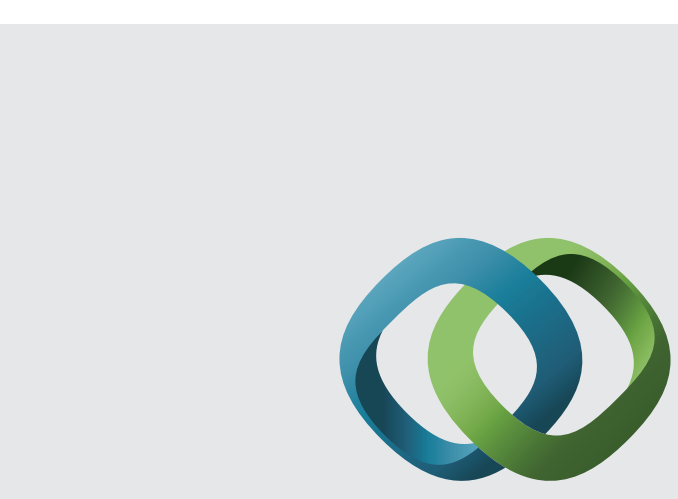

\section{Hindawi}

Submit your manuscripts at

http://www.hindawi.com
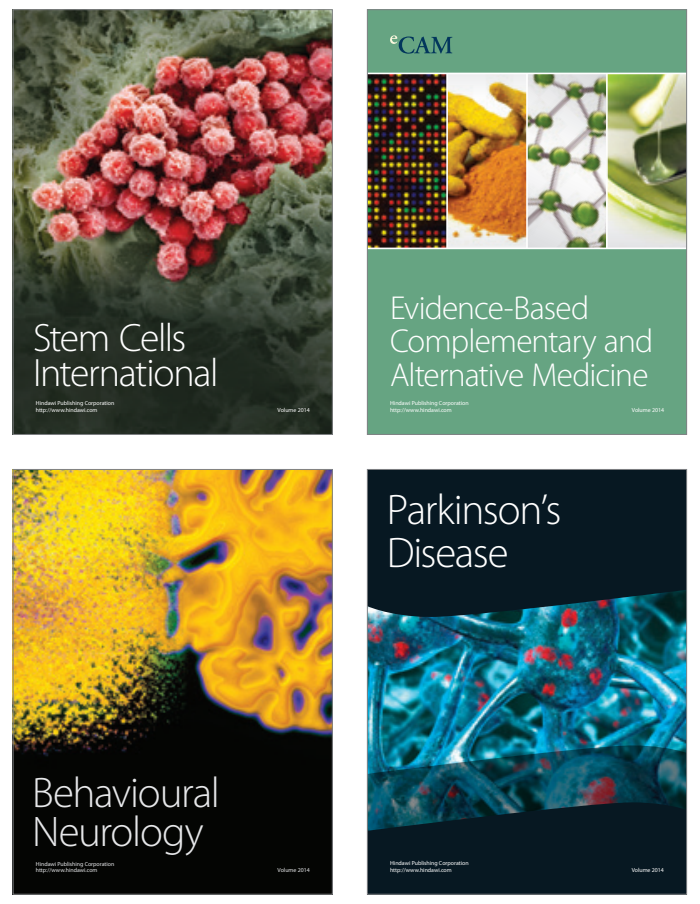
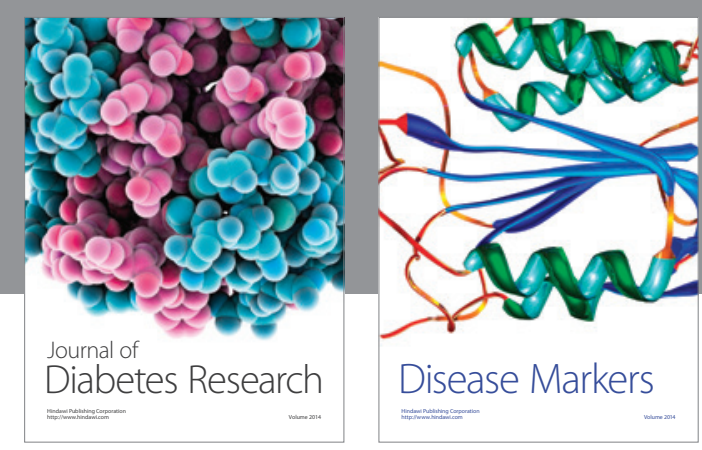

Disease Markers
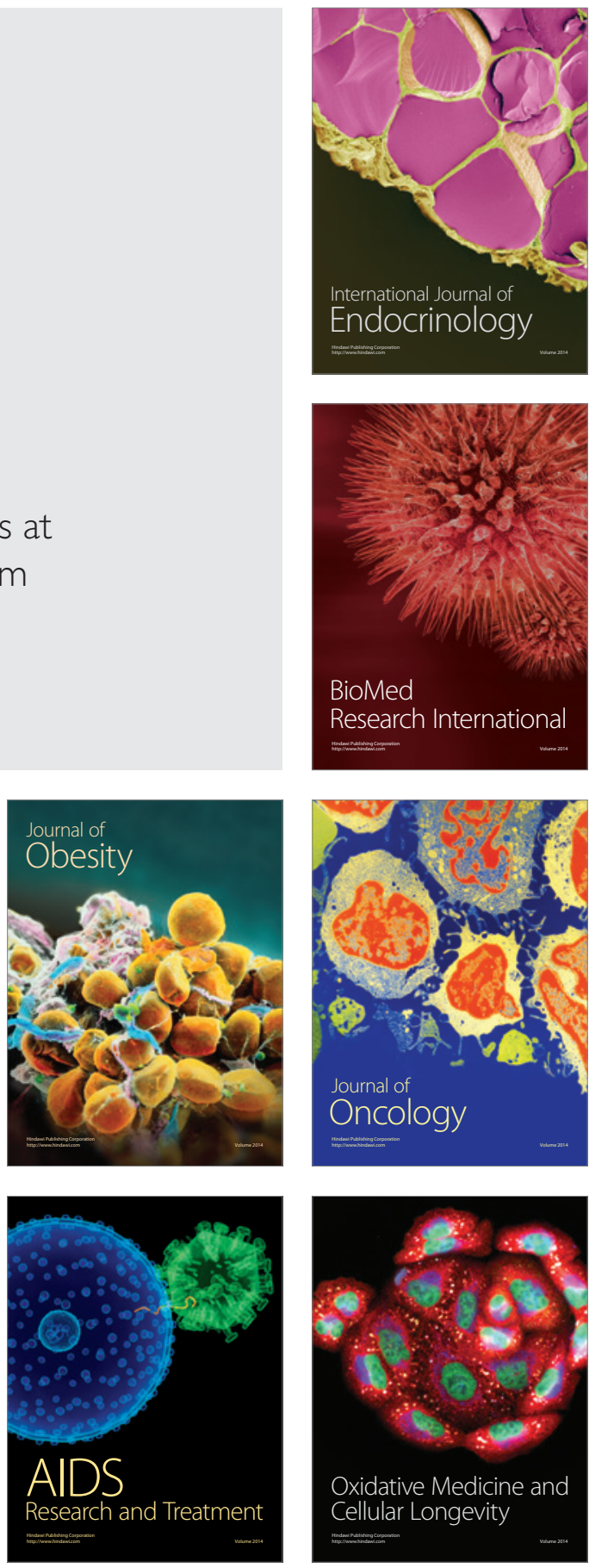